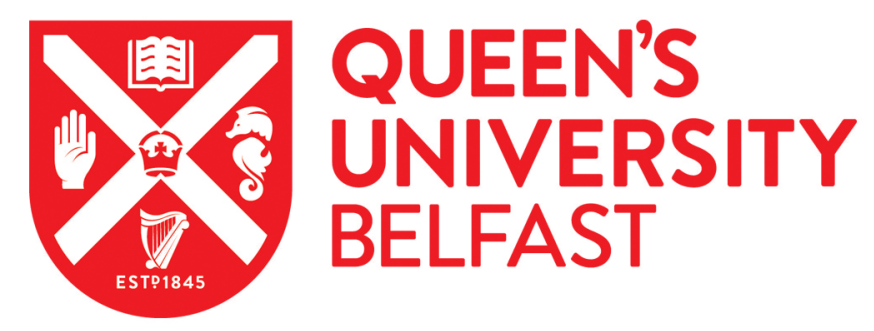

\title{
Sleep quality and prostate cancer aggressiveness Results from the REDUCE trial
}

Wiggins, E. K., Oyekunle, T., Howard, L. E., Markt, S. C., Mucci, L. A., Bliwise, D. L., Moreira, D. M., Andriole, G. L., Hopp, M. L., Freedland, S. J., \& Allott, E. H. (2020). Sleep quality and prostate cancer aggressiveness Results from the REDUCE trial. Prostate. https://doi.org/10.1002/pros.24052

\section{Published in:}

Prostate

\section{Document Version:}

Peer reviewed version

Queen's University Belfast - Research Portal:

Link to publication record in Queen's University Belfast Research Portal

\section{Publisher rights}

Copyright 2020 Wiley. This work is made available online in accordance with the publisher's policies. Please refer to any applicable terms of use of the publisher.

\section{General rights}

Copyright for the publications made accessible via the Queen's University Belfast Research Portal is retained by the author(s) and / or other copyright owners and it is a condition of accessing these publications that users recognise and abide by the legal requirements associated with these rights.

Take down policy

The Research Portal is Queen's institutional repository that provides access to Queen's research output. Every effort has been made to ensure that content in the Research Portal does not infringe any person's rights, or applicable UK laws. If you discover content in the Research Portal that you believe breaches copyright or violates any law, please contact openaccess@qub.ac.uk. 
Sleep quality and prostate cancer aggressiveness: Results from the REDUCE Trial Emily K. Wiggins, $\mathrm{MPH}^{1}$, Taofik Oyekunle, $\mathrm{MS}^{2}$, Lauren E. Howard, $\mathrm{MS}^{2}$, Sarah C. Markt, $\mathrm{ScD}^{3}$, Lorelei A. Mucci, $\mathrm{ScD}^{4}$, Donald Bliwise, $\mathrm{PhD}^{5}$, Daniel M. Moreira, $\mathrm{MD}^{6}$, Gerald L. Andriole, MD7, Martin L. Hopp, MD $^{8}$, Stephen J. Freedland, MD ${ }^{1,8}$, Emma H. Allott, $\mathrm{PhD}^{9,10}$

${ }^{1}$ Division of Urology, Veterans Affairs Medical Center, Durham, NC

${ }^{2}$ Duke Cancer Institute, Duke University School of Medicine, Durham, NC

${ }^{3}$ Department of Population and Quantitative Health Sciences, Case Western Reserve University School of Medicine, Cleveland, $\mathrm{OH}$

${ }^{4}$ Department of Epidemiology, Harvard T. H. Chan School of Public Health, Boston, MA ${ }^{5}$ Department of Neurology, Emory University School of Medicine, Atlanta, GA

${ }^{6}$ Department of Urology, University of Illinois at Chicago, Chicago, IL

${ }^{7}$ Division of Urologic Surgery, Department of Surgery, Washington University School of Medicine, St. Louis, MO

${ }^{8}$ Cedars-Sinai Medical Center, Los Angeles, CA

${ }^{9}$ Patrick G. Johnston Centre for Cancer Research, Queen's University Belfast, Belfast, United Kingdom

${ }^{10}$ Department of Histopathology and Morbid Anatomy, Trinity Translational Medicine Institute, Trinity College Dublin, Ireland 
Running title: Sleep quality and prostate cancer

Keywords: Sleep quality, sleep disturbance, insomnia, prostate biopsy, prostate cancer, tumor grade

Financial support: Irish Cancer Society John Fitzpatrick Fellowship (E.H. Allott), and NIH 1K24CA160653 (S.J. Freedland)

Corresponding author: Emily K. Wiggins, Durham VA Medical Center, 508 Fulton Street, Durham, NC 27705. Phone: 919-286-0411 ext. 173882; E-mail: emily.wiggins@va.gov

Conflicts of interest: The authors have no conflicts of interest

Word count (text, excluding abstract and references): 3,324

Number of Figures: 1; Number of Tables: 4; Number of Supplementary Tables: 5 


\begin{abstract}
Background

Disrupted sleep has been associated with increased risk of certain cancers. Little data exist in prostate cancer. We tested the association between sleep quality and prostate cancer diagnosis overall and by tumor grade in the REduction by DUtasteride of Prostate Cancer Events (REDUCE) chemoprevention trial. We hypothesized that worse sleep quality would be associated with increased tumor aggressiveness.
\end{abstract}

\title{
Methods
}

At baseline, 5,614 men completed a validated 6-item questionnaire on sleep quality. We generated a composite score categorized into tertiles to measure overall sleep quality and assessed each sleep quality question individually. Logistic regression was used to test associations between baseline sleep quality and overall, low-grade and high-grade prostate cancer diagnosis at 2-year study-mandated biopsy. Models were stratified by nocturia.

\section{Results}

Overall sleep quality was unrelated to overall or low-grade prostate cancer. Worse overall sleep quality was associated with elevated odds of high-grade prostate cancer (ORT3vsT1 1.15; $95 \% \mathrm{Cl} 0.83-1.60$ and $\left.\mathrm{OR}_{\mathrm{T} 2 \mathrm{vs} 11} 1.39 ; 95 \% \mathrm{Cl} 1.01-1.92\right)$. Men reporting trouble falling asleep at night sometimes vs. never had elevated odds of high-grade prostate cancer (OR $1.51 ; 95 \% \mathrm{Cl} 1.08-2.09)$ while trouble staying awake during the day was associated with decreased odds of low-grade prostate cancer (OR 0.65; 95\% Cl 0.49-0.86). Results were similar within strata of nocturia severity. 


\section{Conclusions}

Overall, associations between sleep quality and prostate cancer were inconsistent. However, there was some evidence for a positive association between insomnia and high-grade prostate cancer, and an inverse relationship between daytime sleepiness and low-grade prostate cancer; findings that should be validated by future studies. 


\section{Introduction}

Sleep deficiency is a growing public health concern. Lack of sleep has been linked to several health problems, including cardiovascular disease, diabetes and obesity. ${ }^{[1]}$ Additionally, in 2007, the International Agency for Research on Cancer (IARC) named shift work involving circadian disruption as a probable human carcinogen. ${ }^{[2]}$ According to the National Institutes of Health, 50 to 70 million American adults suffer from a sleep disorder or report habitual insufficient sleep. ${ }^{[3]}$ Insomnia, listed as the most common sleep disorder, is present in $5-15 \%$ of the US population. ${ }^{[4]}$ Sleep apnea, another commonly experienced sleep disorder, has an estimated prevalence of $34-37 \%$ among men 30 to 70 years old. ${ }^{[5]}$ These sleep disturbance disorders have been found to be associated with adverse cardiometabolic risk profiles and outcomes. ${ }^{[3]}$ Further, international crosssectional studies have shown a consistently elevated risk of obesity with shorter sleep duration in both children and adults. ${ }^{[6,7]}$

Although the role of sleep quality and sleep disruption has been examined in other diseases, the role of sleep quality and disruption in cancer and specifically, prostate cancer, is not well understood. A meta-analysis by Chen et al found that sleep duration was not significantly associated with overall cancer risk, while a meta-analysis by Lu et al found longer sleep duration was positively associated with colorectal cancer, but inversely associated with prostate cancer. ${ }^{[8,9]}$ A study by Flynn-Evans et al found a strong positive association between shiftwork and elevated prostate-specific antigen (PSA) levels in men without prostate cancer, ${ }^{[10]}$ while studies by Parent et al and Kubo et al found an elevated risk of prostate cancer in association with night-shift work, ${ }^{[11,12]}$ supporting a possible role for sleep quality and disruption in prostate cancer. 
To better understand this link, we aimed to test the association between sleep quality and prostate cancer diagnosis overall and by tumor grade, using data from the Reduction by Dutasteride of Prostate Cancer Events (REDUCE) study. We hypothesized that worse sleep quality would be associated with increased risk of highgrade prostate cancer.

\section{Materials and Methods}

\section{Study Cohort}

The REDUCE study design has been previously described and involved randomized assignment to dutasteride or placebo treatment arms. The study was approved by the Institutional Review Board at each site and all participants provided informed consent. Eligible men included those $50-75$ years of age, with a serum PSA of $2.5-10 \mathrm{ng} / \mathrm{ml}$ (if $\leq 60$ ) or $3-10 \mathrm{ng} / \mathrm{ml}$ (if $>60$ ), and a single, negative biopsy (6-12 cores) within 6 months before enrollment (independent of trial). Negative prostate cancer diagnoses were confirmed by histopathological review of baseline biopsies at a central facility. A total of 8,122 men were enrolled in the efficacy population of REDUCE. We excluded 1,655 men who had no on-study biopsy, 409 men with incomplete Medical Outcome Study (MOS)-Sleep questionnaire data at baseline, and 444 men missing covariates for multivariable analysis. This resulted in a study cohort of 5,614 men (Figure 1).

\section{Medical Outcomes Study Sleep Scale Score}

The 6-item standard version of the MOS-Sleep questionnaire to assess sleep quality was completed by participants at baseline. ${ }^{[13]}$ The MOS-Sleep 6 -item questionnaire is a validated subset of the MOS-Sleep 12-item version ${ }^{[14]}$ that covers 4 sleep dimensions 
including sleep disturbance, awakening due to shortness of breath or with headache, sleep adequacy, and somnolence (Supplementary Table 1). The questions were "how often did you get enough sleep to feel rested upon waking in the morning", "how often did you awaken short of breath or with a headache?", "how often did you have trouble falling asleep?", "how often did you awaken during your sleep time and have trouble falling asleep again?", "how often did you have trouble staying awake during the day?", and "how often did you get the amount of sleep you needed?" Participants responded to these questions about sleep quality at baseline based on the previous 4 weeks using a 6 -tier scale for each question: 'none of the time', 'a little of the time', 'some of the time', 'a good bit of the time', 'most of the time', or 'all of the time'. In addition to examining responses to individual questions, we also generated a composite sleep score to measure overall sleep quality ${ }^{4}$. This was derived by assigning a score from 1-6 to the response for each question and summing the scores across all 6 questions, with a higher composite sleep score indicating poorer overall sleep quality. This resulted in a composite sleep score with a range of 6-36, which was subsequently categorized into tertiles.

\section{Prostate cancer ascertainment}

Men underwent study-mandated biopsy at 2 and 4 years post-randomization. Biopsies were centrally reviewed and when prostate cancer was present Gleason group was assigned, which we categorized as low grade (Gleason group 1 and 2) vs high grade (Gleason group 3, 4 and 5).

\section{Statistical Analysis}


Baseline characteristics were compared across tertiles of composite sleep score using the Kruskal-Wallis test for continuous variables and the chi-square $\left(\mathrm{x}^{2}\right)$ test for categorical variables. Logistic regression models were used to estimate odds ratios (ORs) and 95\% confidence intervals (Cls) of the association between baseline sleep quality and prostate cancer diagnosis at 2 and 4 year biopsy among the entire cohort and within treatment arm (dutasteride vs. placebo). Multinomial logistic regression was used to test the association between baseline sleep quality and low-grade and high-grade prostate cancer (at 2 and 4 year biopsy) relative to no cancer. Baseline sleep quality was assessed using tertiles of the composite score which encompassed responses to all six questions. We also examined responses to individual questions, grouped as "all/most of the time", "some/good bit of the time" and "a little/none of the time", treating the category indicating the best sleep quality for each question as the reference category. To assess the possibility of reverse causation due to symptoms of sub-clinical prostate cancer that could affect sleep, we performed analyses among men stratified by IPSS (<8 vs. $\geq 8$ ) and by nocturia (voiding $<3$ vs. 3 or more times per night ${ }^{[15]}$ ). We tested for interaction between sleep score and categorical IPSS score as well as the interaction between sleep score and nocturia in predicting our outcomes using a Wald test. We also performed analysis stratified by age at randomization ( $<60$ vs. $\geq 60$ years of age) and tested for interaction between sleep score and age at randomization in predicting prostate cancer diagnosis. Finally, to assess whether sleep was related to prostate cancer diagnosis via differential biopsy compliance, we explored the relationship of sleep score to the likelihood of receiving an on-study biopsy. We generated age-adjusted and multivariable models adjusted for age, race (white, black, other), region (North America, Europe, other), digital 
rectal examination (DRE; normal or abnormal), family history of prostate cancer (yes, no), prostate volume (continuous, log transformed), PSA (continuous, log transformed), body mass index (BMI; continuous), IPSS (continuous), coronary artery disease (yes, no), diabetes (yes, no), daily alcohol intake (continuous) and treatment arm. All adjustment variables were measured at baseline.

Analyses were performed with SAS version 9.4 with $p<0.05$ considered statistically significant.

\section{Results}

Median age at randomization was 63 years (IQR 58-67), 92\% of subjects were white and $61 \%$ were from Europe. Table 1 compares characteristics of REDUCE participants by tertiles of composite sleep score. Men with worse sleep quality (i.e. scores in the highest tertile) were slightly younger at randomization $(p=0.012)$, less likely to be white $(p=0.008)$, and more likely to be North American $(p=0.001)$. They were also more likely to be hypertensive $(p=0.012)$ and have coronary artery disease $(p<0.001)$. Finally, men with greater sleep disturbance had a higher IPSS score at randomization and were more likely to suffer from nocturia (both $p<0.001$ ), though prostate volume and PSA level did not differ across tertiles of composite sleep score (Table 1). Obesity and diabetes status, as well as smoking and alcohol consumption, were similar across tertiles of sleep score ( $p \geq$ $0.088)$.

Overall, we found no evidence for any association between overall sleep score and either overall or low-grade prostate cancer diagnosis at 2-year or 4-year biopsy (Table 2). While there was a suggestion of a positive association between sleep score and high-grade 
prostate cancer at 2-year biopsy, this association was stronger and only significant for the middle - but not upper - tertile of sleep score and only reached statistical significance for the overall cohort (OR 1.39; $95 \% \mathrm{Cl} 1.01-1.92)$ and not when stratified by treatment arm (dutasteride: OR 1.33; 95\% 0.83-2.13; placebo: OR 1.46; 95\% Cl 0.94-2.28). There was no relationship between sleep score and high-grade prostate cancer at 4-year biopsy (Table 2).

Similar to our results by baseline sleep score, we did not observe any consistent associations between sleep quality and prostate cancer when examining each item of the MOS-Sleep questionnaire individually (Table 3). However, trouble staying awake during the day some or a good bit of the time, relative to a little or none of the time, was found to be associated with decreased odds of overall (OR $0.73,95 \% \mathrm{Cl} 0.58-0.91, p=0.006$ ) and low-grade (OR $0.65,95 \% \mathrm{Cl} 0.49-0.86, \mathrm{p}=0.002)$ prostate cancer at 2-year biopsy. These associations were attenuated and no longer significant for men who reported trouble staying awake all or most of the time, relative to a little or none of the time $(p \geq 0.278)$. Conversely, trouble falling asleep at night some or a good bit of the time was associated with increased odds of high-grade prostate cancer (OR 1.51, 95\% Cl 1.06$2.09, p=0.014$ ) with a similar magnitude of effect observed for men reporting this problem all or most of the time (OR $1.61 ; 95 \% \mathrm{Cl} 0.95-2.72 ; \mathrm{p}=0.078)$, though it did not reach statistical significance. Similarly, awakening during sleep time and trouble falling back asleep some or a good bit of the time was associated with elevated odds of high-grade prostate cancer (OR 1.32; 95\% Cl 0.99-1.77; $\mathrm{p}=0.059)$. Baseline sleep quality was not associated with overall, low-grade, or high-grade prostate cancer at 4-year biopsy (Supplementary Table 2). 
Associations did not vary significantly by IPSS category (<8 vs. $\geq 8$; Supplementary Table 3), by nocturia status (Supplementary Table 4), or by age at randomization (Supplementary Table 5). Of the 7,604 men who completed the MOS-sleep questionnaire at baseline, after adjustment for potential confounders, a baseline sleep score in the upper vs. lower tertile (i.e., worse overall sleep quality) was associated with a lower likelihood of having any on-study biopsy (OR 0.94, 95\% Cl 0.72-0.97, p=0.020, Table 4). Of the 5,181 men who had a negative biopsy at 2-years and thus were eligible to receive a biopsy at 4-years, sleep disturbance was not associated with the likelihood receiving a biopsy at 4-years (all $p \geq 0.221$ ).

\section{Discussion}

In this secondary analysis of data from the REDUCE trial, we tested the association between sleep quality and prostate cancer diagnosis at 2-year and 4-year studymandated biopsies, overall and by tumor grade. Overall, we found no association between overall sleep quality and overall or low-grade prostate cancer diagnosis, whereas there was some evidence for a positive association between worse overall sleep quality and increased odds of high-grade prostate cancer diagnosis. Although no consistent patterns of association were seen on examining individual aspects of sleep quality, we found some evidence for an inverse association between trouble staying awake during the day and low-grade prostate cancer diagnosis. We also found some evidence for a positive association between trouble falling asleep at night and highgrade prostate cancer diagnosis. Our findings provide some suggestive evidence supporting a potential association between certain aspects of sleep quality related to 
daytime drowsiness, symptoms of insomnia and prostate cancer aggressiveness which merit further exploration by future studies.

Previous studies have explored the association between sleep duration, one aspect of sleep quality, and prostate cancer risk but with mixed results. The most recent metaanalysis by Chen et al including these amongst 65 studies total revealed that neither short nor long sleep duration was associated with increased overall cancer risk. ${ }^{\left[{ }^{8}\right]}$ Four studies examining prostate cancer risk were included in this meta-analysis and when summarized, no association was shown between either short sleep duration (defined as $<7$ hours of sleep per night; OR $0.95 ; 95 \% \mathrm{Cl} 0.86-1.04$ ) or long sleep duration (defined as >9 hours of sleep; OR $0.75 ; 95 \% \mathrm{Cl} 0.54-1.05)$ and prostate cancer risk. ${ }^{\left[{ }^{8]}\right.}$ Though only four individual studies of prostate cancer contributed to this meta-analysis, all four were large prospective studies. ${ }^{[1,16-18]}$ While Kakizaki et al found an inverse association between longer sleep duration (9 hours of sleep or more per night within the previous year) and the risk of prostate cancer in Japanese men, ${ }^{[17]}$ two US-based studies found no relationship between sleep duration and prostate cancer risk. ${ }^{[1,16]}$ These null findings were in keeping with another prospective study from Sweden showing no association between sleep duration and prostate cancer risk. ${ }^{[18]}$ Another prospective US study by Gapstur et al not included in the Chen meta-analysis found that short sleep duration was associated with higher risk of fatal prostate cancer during the first 8 years of followup. ${ }^{[19]}$ Therefore, although relatively few studies have been conducted to date, most have aimed to draw associations between sleep duration and prostate cancer risk, and fewer have examined the role of sleep quality in prostate cancer. 
Beyond assessing sleep duration, there may be other more informative measures of sleep quality. Sleep disruption has been assessed in a number of epidemiological studies using similar questions to those asked in REDUCE. In a large prospective study of US health professionals, Markt et al found no association between several measures of sleep quality, including waking up during the night, difficulty falling asleep, or waking up too early, and risk of prostate cancer. ${ }^{[1]}$ However, men who reported never feeling rested when they woke up had an increased risk of lethal prostate cancer when compared to those who reported feeling rested when they woke up ${ }^{[1]}$ In contrast, we found no relationship between getting enough sleep to feel rested in the morning and prostate cancer diagnosis. Our findings regarding a positive association between trouble falling asleep and high-grade prostate cancer is in line with the findings of Sigurdardottir et al, who found that men who had problems falling and staying asleep were at significantly increased risk of prostate cancer, particularly advanced prostate cancer. ${ }^{[20]}$.

Additionally, two studies using data from the National Health Insurance system in Taiwan by Fang et al and Chung et al explored the link between patients with sleep disorders such as insomnia, sleep apnea, and parasomnia and found that patients diagnosed with these sleep disorders were at a higher risk of developing prostate cancer. ${ }^{[21]}$ Together, our suggestive findings in combination with results from these studies may support a link between sleep quality and risk of prostate cancer.

There are several hypotheses regarding the biological underpinnings of sleep and its relationship to prostate cancer. One theory involves the role of circadian rhythm in cancer biology. Disruption of the circadian system, especially in settings such as shift 
work when individuals may be working irregular hours, has been hypothesized to increase cancer risk. ${ }^{[2,22]}$ This has largely been studied in hormone-dependent cancers, as agents that disrupt the circadian rhythm may also alter hormone levels. ${ }^{[2]} \mathrm{A}$ consortium paper by Gu et al found genetic variation in nine core circadian rhythm genes to be associated with prostate cancer, ${ }^{[23]}$ providing genetic epidemiology support for this hypothesis. Of epidemiological studies exploring disruption to circadian rhythm via shift work, a study by Parent et al examining the relationship between cancer and shift work in Canadian men found that the OR for prostate cancer in men who ever worked at night was 2.77 (95\% $\mathrm{Cl} 1.96-3.92)$ when compared to men who never worked at night. ${ }^{[12]}$ Similarly, the Kubo et al study found that, compared with day workers, rotating-shift workers were significantly at risk for prostate cancer (RR 3.0; 95\% Cl 1.27.7). ${ }^{[11]} \mathrm{A}$ meta-analysis by Du et al found no clear association between night shift work and prostate cancer, but subgroup analysis suggested that night shift work may increase the risk of prostate cancer in Asian men (RR 2.45; 95\% Cl 1.19-5.04). ${ }^{[24]}$ However, a Finnish twin cohort study by Dickerman et al found no significant association between shift work and prostate cancer risk in overall analyses. However, a sub-analysis suggested that shift work may be associated with increased risk in "evening types" but not "morning" types, ${ }^{[25]}$ suggesting that chronotype should be considered when assessing the relationship between sleep patterns and prostate cancer risk. However, we did not have access to data regarding work hours or chronotype in the present study, and future studies are required to test this hypothesis in the context of disruptions to circadian rhythm. 
An additional factor affecting sleep and prostate cancer risk is stress and anxiety. When cortisol, the primary stress hormone, is secreted, it is known to have immunosuppressive effects and lead to depressed mood. ${ }^{[26]}$ Further, cortisol levels have been shown to be elevated in men with prostate cancer. ${ }^{[27]}$ Poor sleep quality may act as a surrogate measure of stress, capturing a relationship between chronic stress rather than sleep disruption and prostate cancer. Finally, melatonin levels may also contribute to the potential link between sleep and prostate cancer. Melatonin is produced at night and when disturbed by light, its production is temporarily inhibited. ${ }^{[28]}$ Shorter sleep duration is associated with decreased levels of melatonin. ${ }^{[29]}$ Melatonin has been shown to suppress the initiation phase of tumorigenesis ${ }^{[22]}$ and inhibit the proliferation of cancer cells. ${ }^{[8]}$ Melatonin has the ability to act as a free radical scavenger and may promote the repair of DNA once damage has occurred. ${ }^{[22]}$ A study by Sigurdardottir et al showed that men who reported sleep problems had lower melatonin metabolites in their first morning urine compared with those who reported no sleep problems. Men with morning melatonin metabolite levels below the median showed a fourfold statistically significant increased risk for advanced prostate cancer disease compared with men with levels above the median (HR 4.04; 95\% Cl 1.26-12.98). ${ }^{[30]}$ Thus, it is possible that sleep disruption may increase the risk of prostate cancer in part via low melatonin levels which we were unable to measure in the present study.

This study had several strengths and limitations. First, information about sleep quality was self-reported. However, it is unlikely that any potential misclassification would be associated with prostate cancer diagnosis, as sleep quality was reported prior to prostate cancer diagnosis. We also found evidence that worse sleep quality was 
associated with lower biopsy compliance, which may have biased our findings in favor of an inverse association between sleep quality and prostate cancer diagnosis. This could have contributed to the observed inverse association between daytime drowsiness and overall prostate cancer. In addition, this potential bias may have attenuated associations between sleep quality and aggressive prostate cancer which potentially contributed to our relatively null findings. Although the reasons for any lack of compliance with the on-study biopsies was not collected in REDUCE, it may be that men reporting poor quality sleep also had other health issues or characteristics that negatively affected their biopsy compliance. We previously published that a variety of characteristics measured at baseline affected the likelihood of biopsy compliance in REDUCE, including IPSS score, region and treatment center ${ }^{\left[{ }^{[31]}\right.}$ Additionally, we performed a relatively large number of statistical tests and we did not adjust our results for multiple testing, thereby raising the likelihood of type I error. As such, our findings relating daytime drowsiness and symptoms of insomnia to prostate cancer should be viewed with caution. Additionally, the REDUCE study has a majority white sample population, which is a limitation given the higher burden of prostate cancer in men African of descent and the unmet need to identify risk factors for prostate cancer in this group. ${ }^{[32]}$ Finally, the follow-up period in REDUCE is relatively short, preventing the study of potential longer-term effects of sleep quality on prostate cancer risk. The strengths of this study included our access to data on IPSS and nocturia, which enabled stratified analyses to test associations in men with and without urinary symptoms, which may negatively affect sleep quality and be an early indicator of prostate cancer. Finally, 
PSA-independent study-mandated biopsies in REDUCE ensured that PSA screening was not a confounder in our analysis.

\section{Conclusions}

In conclusion, overall sleep quality was not consistently associated with overall prostate cancer or with tumor aggressiveness in REDUCE. Considering individual aspects of sleep quality, trouble staying awake during the day was inversely associated with lowgrade prostate cancer. The clinical relevance of this is unknown. Interestingly, symptoms of insomnia were positively associated with high-grade, but not with overall or low-grade prostate cancer. Whether this reflects type I error, dysfunctional or inadequate sleep, or is related to other causes of insomnia (anxiety/stress/etc.) requires further study. Future studies should further investigate the effect of sleep disturbance on prostate cancer risk. 


\section{References}

1. Markt, S.C., et al., Sleep duration and disruption and prostate cancer risk: a 23-year prospective study. Cancer Epidemiology and Prevention Biomarkers, 2016. 25(2): p. 302-308.

2. Painting, F., IARC monographs on the evaluation of carcinogenic risks to humans. 2010.

3. St-Onge, M.P., et al., Sleep Duration and Quality: Impact on Lifestyle Behaviors and Cardiometabolic Health: A Scientific Statement From the American Heart Association. Circulation, 2016. 134(18): p. e367-e386.

4. Ohayon, M.M., Epidemiology of insomnia: what we know and what we still need to learn. Sleep medicine reviews, 2002. 6(2): p. 97-111.

5. Peppard, P.E., et al., Increased prevalence of sleep-disordered breathing in adults. American journal of epidemiology, 2013. 177(9): p. 1006-1014.

6. Cappuccio, F.P., et al., Meta-analysis of short sleep duration and obesity in children and adults. Sleep, 2008. 31(5): p. 619-626.

7. Patel, S., Reduced sleep as an obesity risk factor. Obesity Reviews, 2009. 10: p. 61-68.

8. Chen, Y., et al., Sleep duration and the risk of cancer: a systematic review and meta-analysis including dose-response relationship. BMC cancer, 2018. 18(1): p. 1149.

9. Lu, Y., et al., Association between sleep duration and cancer risk: a meta-analysis of prospective cohort studies. PloS one, 2013. 8(9): p. e74723.

10. Flynn-Evans, E.E., et al., Shiftwork and prostate-specific antigen in the National Health and Nutrition Examination Survey. Journal of the National Cancer Institute, 2013. 105(17): p. 12921297.

11. Kubo, T., et al., Prospective cohort study of the risk of prostate cancer among rotating-shift workers: findings from the Japan collaborative cohort study. American journal of epidemiology, 2006. 164(6): p. 549-555.

12. Parent, M.-É., et al., Night work and the risk of cancer among men. American journal of epidemiology, 2012. 176(9): p. 751-759.

13. Kim, S.S., et al., Validity of the medical outcomes study sleep scale in patients with painful diabetic peripheral neuropathy in K orea. Journal of diabetes investigation, 2013. 4(4): p. 405409.

14. Viala-Danten, M., et al., Evaluation of the reliability and validity of the Medical Outcomes Study sleep scale in patients with painful diabetic peripheral neuropathy during an international clinical trial. Health and Quality of Life outcomes, 2008. 6(1): p. 113.

15. Bliwise, D.L., et al., Nocturia and associated mortality: observational data from the REDUCE trial. Prostate Cancer Prostatic Dis, 2019. 22(1): p. 77-83.

16. Gu, F., et al., Sleep duration and cancer in the NIH-AARP diet and health study cohort. PloS one, 2016. 11(9): p. e0161561.

17. Kakizaki, M., et al., Sleep duration and the risk of prostate cancer: the Ohsaki Cohort Study. British journal of cancer, 2008. 99(1): p. 176.

18. Markt, S.C., et al., Insufficient sleep and risk of prostate cancer in a large Swedish cohort. Sleep, 2015. 38(9): p. 1405-1410.

19. Gapstur, S.M., et al., Work schedule, sleep duration, insomnia, and risk of fatal prostate cancer. American journal of preventive medicine, 2014. 46(3): p. S26-S33.

20. Sigurdardottir, L.G., et al., Sleep disruption among older men and risk of prostate cancer. Cancer Epidemiology and Prevention Biomarkers, 2013. 22(5): p. 872-879.

21. Fang, H.-F., et al., Risk of cancer in patients with insomnia, parasomnia, and obstructive sleep apnea: a nationwide nested case-control study. Journal of Cancer, 2015. 6(11): p. 1140. 
22. Blask, D.E., Melatonin, sleep disturbance and cancer risk. Sleep medicine reviews, 2009. 13(4): p. 257-264.

23. Gu, F., et al., Inherited variation in circadian rhythm genes and risks of prostate cancer and three other cancer sites in combined cancer consortia. International journal of cancer, 2017. 141(9): p. 1794-1802.

24. Du, H.-B., et al., Shift work, night work, and the risk of prostate cancer: a meta-analysis based on 9 cohort studies. Medicine, 2017. 96(46).

25. Dickerman, B.A., et al., Sleep disruption, chronotype, shift work, and prostate cancer risk and mortality: a 30-year prospective cohort study of Finnish twins. Cancer Causes \& Control, 2016. 27(11): p. 1361-1370.

26. Carlson, L.E., et al., Mindfulness-based stress reduction in relation to quality of life, mood, symptoms of stress and levels of cortisol, dehydroepiandrosterone sulfate (DHEAS) and melatonin in breast and prostate cancer outpatients. Psychoneuroendocrinology, 2004. 29(4): p. 448-474.

27. Fabre, B., et al., Prostate cancer, high cortisol levels and complex hormonal interaction. 2016.

28. Sigurdardottir, L.G., et al., Circadian disruption, sleep loss, and prostate cancer risk: a systematic review of epidemiologic studies. Cancer Epidemiology and Prevention Biomarkers, 2012. 21(7): p. 1002-1011.

29. Fritschi, L., et al., Hypotheses for mechanisms linking shiftwork and cancer. Medical hypotheses, 2011. 77(3): p. 430-436.

30. Sigurdardottir, L.G., et al., Urinary melatonin levels, sleep disruption, and risk of prostate cancer in elderly men. European urology, 2015. 67(2): p. 191-194.

31. Fischer, Sean, et al. "Baseline subject characteristics predictive of compliance with study-mandated prostate biopsy in men at risk of prostate cancer: results from REDUCE." Prostate cancer and prostatic diseases 19.2 (2016): 202-208.

32. Siegel, R.L., K.D. Miller, and A. Jemal, Cancer statistics, 2015. CA: a cancer journal for clinicians, 2015. 65(1): p. 5-29. 
Table 1: Baseline characteristics of 5,614 patients in REDUCE

\begin{tabular}{|c|c|c|c|c|}
\hline & \multicolumn{3}{|c|}{ Sleep score* } & \\
\hline & $\begin{array}{l}\text { Lowest tertile } \\
\qquad \begin{array}{c}(6.0-9.0) \\
\mathrm{N}=2,038\end{array}\end{array}$ & \begin{tabular}{|c|} 
Middle tertile $(>6.0-$ \\
$12.0)$ \\
$\mathrm{N}=1,700$
\end{tabular} & $\begin{array}{c}\text { Highest tertile } \\
(>12.0-36.0) \\
\mathrm{N}=1,876\end{array}$ & $\mathrm{p}$ value \\
\hline Median age at randomization (IQR) & $63(58,67)$ & $63(58,67)$ & $62(57,67)$ & $0.012^{1}$ \\
\hline Race, N (\%) & & & & $0.008^{2}$ \\
\hline White & $1896(93.0 \%)$ & $1593(93.7 \%)$ & $1705(90.9 \%)$ & \\
\hline Black & $24(1.2 \%)$ & $25(1.5 \%)$ & $40(2.1 \%)$ & \\
\hline Others & $118(5.8 \%)$ & $82(4.8 \%)$ & $131(7.0 \%)$ & \\
\hline Geographic Region, N (\%) & & & & $0.001^{2}$ \\
\hline North America & $472(23.2 \%)$ & $484(28.5 \%)$ & $507(27.0 \%)$ & \\
\hline Europe & $1273(62.5 \%)$ & $1023(60.2 \%)$ & $1121(59.8 \%)$ & \\
\hline Other & $293(14.4 \%)$ & $193(11.4 \%)$ & $248(13.2 \%)$ & \\
\hline Family history of PC, N (\%) & $264(13.0 \%)$ & $226(13.3 \%)$ & $255(13.6 \%)$ & $0.840^{2}$ \\
\hline Median no. alcoholic drinks/week, (IQR) & $3(1.0,8.0)$ & $3(1.0,8.0)$ & $3(0.0,8.0)$ & $0.390^{1}$ \\
\hline Smoking status, N (\%) & & & & $0.370^{2}$ \\
\hline Never & $916(44.9 \%)$ & $794(46.7 \%)$ & $824(43.9 \%)$ & \\
\hline Former & $809(39.7 \%)$ & $674(39.6 \%)$ & $775(41.3 \%)$ & \\
\hline Current & $313(15.4 \%)$ & $232(13.6 \%)$ & $277(14.8 \%)$ & \\
\hline Median BMI, (IQR) & $26.7(24.8,29.1)$ & $26.8(24.9,29.4)$ & $27.0(24.9,29.4)$ & $0.088^{1}$ \\
\hline Hypertension, N (\%) & $430(21.1 \%)$ & $387(22.8 \%)$ & $471(25.1 \%)$ & $0.012^{2}$ \\
\hline Statin use (ever), N (\%) & $347(17.0 \%)$ & $299(17.6 \%)$ & $351(18.7 \%)$ & $0.378^{2}$ \\
\hline Diabetes status, N (\%) & $115(5.6 \%)$ & $79(4.6 \%)$ & $111(5.9 \%)$ & $0.215^{2}$ \\
\hline Coronary artery disease, N (\%) & $140(6.9 \%)$ & $120(7.1 \%)$ & $187(10.0 \%)$ & $<0.001^{2}$ \\
\hline Suspicious DRE, N (\%) & & & & $0.660^{2}$ \\
\hline Normal/enlarged & $1968(96.6 \%)$ & $1633(96.1 \%)$ & $1811(96.5 \%)$ & \\
\hline Abnormal & $70(3.4 \%)$ & $67(3.9 \%)$ & $65(3.5 \%)$ & \\
\hline Median biopsy IPSS, (IQR) & $6.0(3.0,10.0)$ & $7.0(4.0,12.0)$ & $9.0(5.0,14.0)$ & $<0.001^{1}$ \\
\hline Nocturia, N (\%) & $222(10.9 \%)$ & $255(15.0 \%)$ & $409(21.8 \%)$ & $<0.001^{2}$ \\
\hline Median Prostate volume, (IQR) & $43.5(33.0,56.4)$ & $43.7(33.3,56.5)$ & $42.4(32.8,55.5)$ & $0.201^{1}$ \\
\hline Median PSA level, (IQR) & $5.7(4.4,7.2)$ & $5.7(4.3,7.3)$ & $5.7(4.4,7.3)$ & $0.917^{1}$ \\
\hline Treatment arm, N (\%) & & & & $0.402^{2}$ \\
\hline Placebo & $1054(51.7 \%)$ & $843(49.6 \%)$ & $962(51.3 \%)$ & \\
\hline Dutasteride $0.5 \mathrm{mg}$ & $984(48.3 \%)$ & $857(50.4 \%)$ & $914(48.7 \%)$ & \\
\hline
\end{tabular}

*derived by assigning a score from 1-6 to the responses for each sleep question and summing the scores across all 6 questions. This resulted in a composite sleep score with a range of 6-36, which was subsequently categorized into tertiles. Higher scores indicate a greater severity of sleep disturbance. 
${ }^{1}$ Kruskal Wallis; ${ }^{2}$ Chi-Square.

Abbreviations: IQR=Inter-Quartile Range; BMI=Body Mass Index; DRE=Digital Rectal Examination; IPSS=International Prostate Symptom Score; PSA=Prostate Specific Antigen; 
Table 2: Association between sleep score at baseline and odds of overall, low-grade and high-grade prostate cancer at 2 and 4 years after randomization in REDUCE, overall and stratified by treatment arm.

\begin{tabular}{|c|c|c|c|c|c|c|c|c|c|}
\hline \multirow{2}{*}{$\begin{array}{l}\text { 2-year biopsy } \\
\text { Overall PC }\end{array}$} & \multicolumn{3}{|c|}{ All patients $(\mathrm{N}=5,614)$} & \multicolumn{3}{|c|}{ Treatment arm $(\mathrm{N}=2,755)$} & \multicolumn{3}{|c|}{ Placebo $\operatorname{Arm}(\mathrm{N}=2,859)$} \\
\hline & $\mathbf{n} / \mathbf{N}$ & $\begin{array}{c}\text { OR (95\% } \\
\text { CI) }\end{array}$ & $\begin{array}{c}\text { p- } \\
\text { value }\end{array}$ & $\mathbf{n} / \mathbf{N}$ & $\begin{array}{c}\text { OR (95\% } \\
\text { CI) }\end{array}$ & $\begin{array}{c}\text { p- } \\
\text { value }\end{array}$ & $\mathbf{n} / \mathbf{N}$ & $\begin{array}{c}\text { OR (95\% } \\
\text { CI) }\end{array}$ & $\begin{array}{c}\text { p- } \\
\text { value }\end{array}$ \\
\hline \multicolumn{10}{|l|}{$\begin{array}{l}\text { Sleep score } \\
\text { (tertiles)** }\end{array}$} \\
\hline Low $(6.0-9.0)$ & $\begin{array}{c}291 / 20 \\
38\end{array}$ & ref & - & $\begin{array}{c}128 / 9 \\
84\end{array}$ & ref & - & $\begin{array}{c}163 / 10 \\
54\end{array}$ & ref & - \\
\hline $\begin{array}{c}\text { Medium } \\
(>6.0-12.0)\end{array}$ & $\begin{array}{c}251 / 17 \\
00\end{array}$ & $\begin{array}{c}1.08(0.89- \\
1.30)\end{array}$ & 0.448 & $\begin{array}{c}102 / 8 \\
57\end{array}$ & $\begin{array}{c}0.96(0.72- \\
1.28)\end{array}$ & 0.769 & $\begin{array}{c}149 / 84 \\
3\end{array}$ & $\begin{array}{c}1.19(0.93- \\
1.53)\end{array}$ & 0.172 \\
\hline $\begin{array}{l}\text { High }(>12.0- \\
36.0)\end{array}$ & $\begin{array}{c}261 / 18 \\
76\end{array}$ & $\begin{array}{c}0.98(0.81- \\
1.19)\end{array}$ & 0.858 & $\begin{array}{c}111 / 9 \\
14\end{array}$ & $\begin{array}{c}0.96(0.72- \\
1.28)\end{array}$ & 0.778 & $\begin{array}{c}150 / 96 \\
2\end{array}$ & $\begin{array}{c}1.01(0.78- \\
1.30)\end{array}$ & 0.956 \\
\hline \multicolumn{10}{|l|}{ Low-grade PC } \\
\hline \multicolumn{10}{|l|}{$\begin{array}{ll}\begin{array}{l}\text { Sleep } \\
\text { (tertiles) }\end{array} & \text { score } \\
\end{array}$} \\
\hline Low $(6.0-9.0)$ & $\begin{array}{c}211 / 20 \\
38\end{array}$ & ref & - & $\begin{array}{c}90 / 98 \\
4\end{array}$ & ref & - & $\begin{array}{c}121 / 10 \\
54\end{array}$ & ref & - \\
\hline $\begin{array}{c}\text { Medium } \\
(>6.0-12.0)\end{array}$ & $\begin{array}{c}165 / 17 \\
00\end{array}$ & $\begin{array}{c}0.97(0.78- \\
1.20)\end{array}$ & 0.747 & $\begin{array}{c}61 / 85 \\
7\end{array}$ & $\begin{array}{c}0.81(0.57- \\
1.15)\end{array}$ & 0.234 & $\begin{array}{c}104 / 84 \\
3\end{array}$ & $\begin{array}{c}1.10(0.83- \\
1.46)\end{array}$ & 0.514 \\
\hline $\begin{array}{l}\text { High }(>12.0- \\
36.0)\end{array}$ & $\begin{array}{c}178 / 18 \\
76\end{array}$ & $\begin{array}{c}0.93(0.74- \\
1.15)\end{array}$ & 0.489 & $\begin{array}{c}74 / 91 \\
4\end{array}$ & $\begin{array}{l}0.92(0.66- \\
1.29)\end{array}$ & 0.625 & $\begin{array}{c}104 / 81 \\
2\end{array}$ & $\begin{array}{c}0.94(0.70- \\
1.25)\end{array}$ & 0.652 \\
\hline \multicolumn{10}{|l|}{ High-grade PC } \\
\hline \multicolumn{10}{|l|}{$\begin{array}{ll}\begin{array}{l}\text { Sleep } \\
\text { (tertiles) }\end{array} & \text { score } \\
\end{array}$} \\
\hline Low $(6.0-9.0)$ & $\begin{array}{c}80 / 203 \\
8\end{array}$ & ref & - & $\begin{array}{c}38 / 98 \\
4\end{array}$ & ref & - & $\begin{array}{c}42 / 105 \\
4\end{array}$ & ref & - \\
\hline $\begin{array}{c}\text { Medium } \\
(>6.0-12.0)\end{array}$ & $\begin{array}{c}86 / 170 \\
0\end{array}$ & $\begin{array}{c}1.39(1.01- \\
1.92)\end{array}$ & 0.045 & $\begin{array}{c}41 / 85 \\
7\end{array}$ & $\begin{array}{c}1.33(0.83- \\
2.13)\end{array}$ & 0.231 & $45 / 843$ & $\begin{array}{c}1.46(0.94- \\
2.28)\end{array}$ & 0.093 \\
\hline $\begin{array}{l}\text { High }(>12.0- \\
36.0)\end{array}$ & $\begin{array}{c}83 / 187 \\
6\end{array}$ & $\begin{array}{c}1.15(0.83- \\
1.60)\end{array}$ & 0.410 & $\begin{array}{c}37 / 91 \\
4\end{array}$ & $\begin{array}{c}1.07(0.65- \\
1.74)\end{array}$ & 0.798 & $46 / 962$ & $\begin{array}{c}1.22(0.78- \\
1.93)\end{array}$ & 0.388 \\
\hline 4-year biopsy & \multicolumn{3}{|c|}{ All patients $(\mathrm{N}=4,021)$} & \multicolumn{3}{|c|}{ Treatment arm $(\mathrm{N}=2,057)$} & \multicolumn{3}{|c|}{ Placebo Arm $(\mathrm{N}=1,964)$} \\
\hline \multirow{2}{*}{\multicolumn{10}{|c|}{$\begin{array}{l}\text { Overall PC } \\
\text { Sleep score } \\
\text { (tertiles) }\end{array}$}} \\
\hline & & & & & & & & & \\
\hline Low $(6.0-9.0)$ & $\begin{array}{c}147 / 14 \\
79\end{array}$ & ref & - & $\begin{array}{c}62 / 73 \\
3\end{array}$ & ref & - & $85 / 746$ & ref & - \\
\hline $\begin{array}{c}\text { Medium } \\
(>6.0-12.0)\end{array}$ & $\begin{array}{c}123 / 12 \\
14\end{array}$ & $\begin{array}{ll}1.04 & (0.80- \\
1.34) & \end{array}$ & 0.787 & $\begin{array}{c}62 / 64 \\
1\end{array}$ & $\begin{array}{l}1.19 \quad(0.81- \\
1.74)\end{array}$ & 0.369 & $61 / 573$ & $\begin{array}{ll}0.93 & (0.65- \\
1.33) & \end{array}$ & 0.691 \\
\hline $\begin{array}{l}\text { High }(>12.0- \\
36.0)\end{array}$ & $\begin{array}{c}120 / 13 \\
28\end{array}$ & $\begin{array}{ll}0.88 & (0.67- \\
1.14) & \\
\end{array}$ & 0.330 & $\begin{array}{c}48 / 68 \\
3\end{array}$ & $\begin{array}{ll}0.80 & (0.53- \\
1.22) & \\
\end{array}$ & 0.302 & $72 / 645$ & $\begin{array}{ll}0.95 & (0.67- \\
1.36) & \\
\end{array}$ & 0.790 \\
\hline \multicolumn{10}{|l|}{ Low-grade PC } \\
\hline \multicolumn{10}{|l|}{$\begin{array}{ll}\begin{array}{l}\text { Sleep } \\
\text { (tertiles) }\end{array} & \text { score } \\
\end{array}$} \\
\hline Low (6.0-9.0) & $\begin{array}{c}106 / 14 \\
79 \\
\end{array}$ & ref & - & $\begin{array}{c}42 / 73 \\
3\end{array}$ & ref & - & $64 / 746$ & ref & - \\
\hline $\begin{array}{c}\text { Medium } \\
(>6.0-12.0)\end{array}$ & $\begin{array}{c}87 / 121 \\
4\end{array}$ & $\begin{array}{ll}1.01 & (0.75- \\
1.36) & \end{array}$ & 0.953 & $\begin{array}{c}41 / 64 \\
1\end{array}$ & $\begin{array}{ll}1.17 & (0.75- \\
1.85) & \end{array}$ & 0.482 & $46 / 573$ & $\begin{array}{ll}0.90 & (0.60- \\
1.36) & \end{array}$ & 0.625 \\
\hline
\end{tabular}




\begin{tabular}{|c|c|c|c|c|c|c|c|c|c|}
\hline $\begin{array}{l}\text { High }(>12.0- \\
36.0)\end{array}$ & $\begin{array}{c}91 / 132 \\
8\end{array}$ & $\begin{array}{ll}0.92 & (0.68- \\
1.25) & \end{array}$ & 0.577 & $\begin{array}{c}30 / 68 \\
3\end{array}$ & $\begin{array}{ll}0.79 & (0.48- \\
1.31) & \end{array}$ & 0.357 & $61 / 645$ & $\begin{array}{ll}1.04 & (0.70- \\
1.53) & \end{array}$ & 0.855 \\
\hline \multicolumn{10}{|l|}{ High-grade PC } \\
\hline \multicolumn{10}{|l|}{$\begin{array}{ll}\begin{array}{l}\text { Sleep } \\
\text { (tertiles) }\end{array} & \text { score } \\
\end{array}$} \\
\hline Low (6.0-9.0) & $\begin{array}{c}41 / 147 \\
9\end{array}$ & ref & - & $\begin{array}{c}20 / 73 \\
3\end{array}$ & ref & - & $21 / 733$ & ref & - \\
\hline $\begin{array}{r}\text { Medium } \\
(>6.0-12.0)\end{array}$ & $\begin{array}{c}36 / 121 \\
4\end{array}$ & $\begin{array}{l}1.12 \quad(0.70- \\
1.79)\end{array}$ & 0.642 & $\begin{array}{c}21 / 64 \\
1\end{array}$ & $\begin{array}{ll}1.22 & (0.64- \\
2.32) & \end{array}$ & 0.542 & $15 / 641$ & $\begin{array}{ll}1.08 & (0.54- \\
2.17) & \end{array}$ & 0.838 \\
\hline $\begin{array}{l}\text { High }(>12.0- \\
36.0)\end{array}$ & $\begin{array}{c}29 / 132 \\
8\end{array}$ & $\begin{array}{ll}0.78 & (0.47- \\
1.29) & \end{array}$ & 0.326 & $\begin{array}{c}18 / 68 \\
3\end{array}$ & $\begin{array}{ll}0.84 & (0.42- \\
1.68) & \end{array}$ & 0.637 & $11 / 683$ & $\begin{array}{ll}0.69 & (0.32- \\
1.50) & \end{array}$ & 0.347 \\
\hline
\end{tabular}

*Adjusted for: Age at Baseline, race, region, DRE, family history of prostate cancer, prostate volume (log transformed), PSA (log transformed), baseline BMI, baseline IPSS, coronary artery disease, diabetes, alcohol use, and treatment arm (for the entire cohort only).

Higher scores indicate a greater severity of sleep disturbance.

$\mathrm{n}=$ number of men with event; $\mathrm{N}=$ Number of men within each group.

**derived by assigning a score from 1-6 to the responses for each sleep question and summing the scores across all 6 questions. This resulted in a composite sleep score with a range of 6-36, which was subsequently categorized into tertiles. Higher scores indicate a greater severity of sleep disturbance. 
Table 3: Association between baseline sleep quality (using individual questions on the 6-item MOS sleep Scale) and odds of overall, low-grade and high-grade prostate cancer at 2-years after randomization in REDUCE.

\begin{tabular}{|c|c|c|c|c|c|c|c|c|c|}
\hline & \multicolumn{3}{|c|}{ Overall PC } & \multicolumn{3}{|c|}{ Low-grade PC } & \multicolumn{3}{|c|}{ High-grade PC } \\
\hline & $\mathbf{n} / \mathbf{N}$ & $\begin{array}{l}\text { OR (95\% } \\
\text { CI) }\end{array}$ & $\begin{array}{c}\text { p- } \\
\text { value }\end{array}$ & $\mathbf{n} / \mathbf{N}$ & $\begin{array}{l}\text { OR }(95 \% \\
\text { CI })\end{array}$ & $\begin{array}{c}\text { p- } \\
\text { value }\end{array}$ & $\mathbf{n} / \mathbf{N}$ & $\begin{array}{l}\text { OR }(95 \% \\
\text { CI })\end{array}$ & $\begin{array}{c}\text { p- } \\
\text { value }\end{array}$ \\
\hline \multicolumn{10}{|c|}{$\begin{array}{l}\text { Q1: Get enough sleep to feel rested } \\
\text { upon waking in the morning }\end{array}$} \\
\hline All/most of the time & $\begin{array}{c}591 / 41 \\
49\end{array}$ & ref & - & $\begin{array}{c}404 / 41 \\
49\end{array}$ & ref & - & $\begin{array}{c}187 / 41 \\
49\end{array}$ & ref & - \\
\hline Some/good bit of the time & $\begin{array}{c}154 / 10 \\
29\end{array}$ & $\begin{array}{l}1.12(0.92- \\
1.37)\end{array}$ & 0.277 & $\begin{array}{c}109 / 10 \\
29\end{array}$ & $\begin{array}{l}1.15(0.91- \\
1.45)\end{array}$ & 0.232 & $\begin{array}{c}45 / 102 \\
9\end{array}$ & $\begin{array}{l}1.04(0.73- \\
1.47)\end{array}$ & 0.836 \\
\hline A little/none of the time & $58 / 436$ & $\begin{array}{l}0.96(0.72- \\
1.30)\end{array}$ & 0.806 & $41 / 436$ & $\begin{array}{l}1.00(0.71- \\
1.41)\end{array}$ & 0.995 & $17 / 436$ & $\begin{array}{c}0.88(0.53- \\
1.48)\end{array}$ & 0.638 \\
\hline \multicolumn{10}{|c|}{$\begin{array}{l}\text { Q2: Awaken short of breath or with a } \\
\text { headache }\end{array}$} \\
\hline A little/none of the time & $\begin{array}{c}732 / 51 \\
37\end{array}$ & ref & - & $\begin{array}{c}507 / 51 \\
37\end{array}$ & ref & - & $\begin{array}{c}225 / 51 \\
37\end{array}$ & ref & - \\
\hline Some/good bit of the time & $51 / 336$ & $\begin{array}{l}1.03(0.75- \\
1.42)\end{array}$ & 0.835 & $36 / 336$ & $\begin{array}{l}1.08(0.75- \\
1.57)\end{array}$ & 0.666 & $15 / 336$ & $\begin{array}{l}0.93(0.53- \\
1.62)\end{array}$ & 0.783 \\
\hline All/most of the time & $20 / 141$ & $\begin{array}{c}0.88(0.54- \\
1.43) \\
\end{array}$ & 0.593 & $11 / 141$ & $\begin{array}{c}0.72(0.38- \\
1.36) \\
\end{array}$ & 0.311 & $9 / 141$ & $\begin{array}{l}1.19(0.58- \\
2.43)\end{array}$ & 0.629 \\
\hline \multicolumn{10}{|l|}{ Q3: Have trouble falling asleep } \\
\hline A little/none of the time & $\begin{array}{c}616 / 44 \\
56\end{array}$ & ref & - & $\begin{array}{c}438 / 44 \\
56\end{array}$ & ref & - & $\begin{array}{c}178 / 44 \\
56\end{array}$ & ref & - \\
\hline Some/good bit of the time & $\begin{array}{c}147 / 90 \\
6 \\
\end{array}$ & $\begin{array}{c}1.20(0.98- \\
1.47) \\
\end{array}$ & 0.075 & 93/906 & $\begin{array}{c}1.08(0.85- \\
1.38)\end{array}$ & 0.532 & $54 / 906$ & $\begin{array}{l}1.51(1.08- \\
2.09)\end{array}$ & 0.014 \\
\hline All/most of the time & $40 / 252$ & $\begin{array}{c}1.09(0.77- \\
1.56)\end{array}$ & 0.628 & $23 / 252$ & $\begin{array}{c}0.90(0.57- \\
1.40)\end{array}$ & 0.633 & $17 / 252$ & $\begin{array}{l}1.61(0.95- \\
2.72)\end{array}$ & 0.078 \\
\hline \multicolumn{10}{|c|}{$\begin{array}{l}\text { Q4: Awaken during your sleep time and } \\
\text { have trouble falling asleep again? }\end{array}$} \\
\hline A little/none of the time & $\begin{array}{c}551 / 38 \\
89\end{array}$ & ref & - & $\begin{array}{c}393 / 38 \\
89\end{array}$ & ref & - & $\begin{array}{c}158 / 38 \\
89\end{array}$ & ref & - \\
\hline Some/good bit of the time & $\begin{array}{c}220 / 14 \\
66\end{array}$ & $\begin{array}{l}1.05(0.88- \\
1.25)\end{array}$ & 0.581 & $\begin{array}{c}142 / 14 \\
66\end{array}$ & $\begin{array}{l}0.95(0.77- \\
1.17)\end{array}$ & 0.611 & $\begin{array}{c}78 / 146 \\
6\end{array}$ & $\begin{array}{l}1.32(0.99- \\
1.77)\end{array}$ & 0.059 \\
\hline All/most of the time & $32 / 259$ & $\begin{array}{c}0.80(0.54- \\
1.18)\end{array}$ & 0.264 & $19 / 259$ & $\begin{array}{l}0.68(0.42- \\
1.10)\end{array}$ & 0.114 & $13 / 259$ & $\begin{array}{l}1.14(0.63- \\
2.06)\end{array}$ & 0.660 \\
\hline \multicolumn{10}{|c|}{$\begin{array}{l}\text { Q5: Have trouble staying awake during } \\
\text { the day }\end{array}$} \\
\hline A little/none of the time & $\begin{array}{c}678 / 45 \\
69\end{array}$ & ref & - & $\begin{array}{c}473 / 45 \\
69\end{array}$ & ref & - & $\begin{array}{c}205 / 45 \\
69\end{array}$ & ref & - \\
\hline Some/good bit of the time & $\begin{array}{c}104 / 88 \\
7\end{array}$ & $\begin{array}{l}0.73(0.58- \\
0.91)\end{array}$ & 0.006 & $64 / 887$ & $\begin{array}{l}0.65(0.49- \\
0.86)\end{array}$ & 0.002 & $40 / 887$ & $\begin{array}{c}0.91(0.63- \\
1.30)\end{array}$ & 0.493 \\
\hline All/most of the time & $21 / 158$ & $\begin{array}{l}0.77(0.48- \\
1.24)\end{array}$ & 0.278 & $17 / 158$ & $\begin{array}{l}0.91(0.54- \\
1.53)\end{array}$ & 0.712 & $4 / 158$ & $\begin{array}{l}0.47(0.17- \\
1.30)\end{array}$ & 0.144 \\
\hline \multicolumn{10}{|l|}{$\begin{array}{l}\text { Q6: Get the amount of sleep you } \\
\text { needed }\end{array}$} \\
\hline All/most of the time & $\begin{array}{c}614 / 41 \\
52 \\
\end{array}$ & ref & - & $\begin{array}{c}419 / 41 \\
52 \\
\end{array}$ & ref & - & $\begin{array}{c}195 / 41 \\
52 \\
\end{array}$ & ref & - \\
\hline Some/good bit of the time & $\begin{array}{c}116 / 88 \\
0\end{array}$ & $\begin{array}{l}0.95(0.76- \\
1.18)\end{array}$ & 0.624 & $86 / 880$ & $\begin{array}{l}1.03(0.80- \\
1.32)\end{array}$ & 0.835 & $30 / 880$ & $\begin{array}{l}0.76(0.51- \\
1.14)\end{array}$ & 0.187 \\
\hline A little/none of the time & $73 / 582$ & $\begin{array}{c}0.87(0.67- \\
1.13)\end{array}$ & 0.299 & $49 / 582$ & $\begin{array}{l}0.85(0.62- \\
1.17)\end{array}$ & 0.328 & $24 / 582$ & $\begin{array}{c}0.91(0.58- \\
1.42)\end{array}$ & 0.671 \\
\hline
\end{tabular}


Table 4: Associations between sleep score at baseline and the likelihood of receiving an on-study biopsy in REDUCE.

\begin{tabular}{|l|c|c|}
\hline Likelihood of receiving: & OR (95\% CI) & p-value \\
\hline At least one biopsy during the study period. & & \\
\hline Sleep score (tertiles) & ref & \\
\hline Low & $0.93(0.80-1.08)$ & 0.350 \\
\hline Medium & $0.94(0.72-0.97)$ & 0.020 \\
\hline High & & \\
\hline A second biopsy at 4 years after a negative biopsy at 2 years. & ref & \\
\hline Sleep score (tertiles) & $0.96(0.79-1.18)$ & 0.698 \\
\hline Low & $0.89(0.73-1.07)$ & 0.221 \\
\hline Medium & & \\
\hline High & & \\
\hline
\end{tabular}

*Adjusted for: Age at Baseline, race, region, DRE, family history of prostate cancer, diabetes, coronary artery disease, alcohol use, prostate volume (log transformed), PSA (log transformed), baseline BMI, IPSS and treatment arm. 
Supplementary Table 1: Response categories and corresponding scores assigned to each of individual questions in the Medical Outcome Study Six-Item Sleep Scale (6-item standard version),

\begin{tabular}{|c|c|c|c|c|c|c|}
\hline & $\begin{array}{l}\text { All of the } \\
\text { time }\end{array}$ & $\begin{array}{l}\text { Most of } \\
\text { the time }\end{array}$ & $\begin{array}{l}\text { A good bit } \\
\text { of the time }\end{array}$ & $\begin{array}{l}\text { Some of } \\
\text { the time }\end{array}$ & $\begin{array}{c}\text { A little } \\
\text { of the } \\
\text { time }\end{array}$ & $\begin{array}{l}\text { None of } \\
\text { the time }\end{array}$ \\
\hline $\begin{array}{l}\text { MOS-1: Get enough sleep to feel rested upon waking in the } \\
\text { morning? }\end{array}$ & 1 & 2 & 3 & 4 & 5 & 6 \\
\hline $\begin{array}{l}\text { MOS-2: Awaken short of breath or with a } \\
\text { headache? }\end{array}$ & 6 & 5 & 4 & 3 & 2 & 1 \\
\hline MOS-3: Have trouble falling asleep? & 6 & 5 & 4 & 3 & 2 & 1 \\
\hline MOS-5: Have trouble staying awake during the day? & 6 & 5 & 4 & 3 & 2 & 1 \\
\hline MOS-6: Get the amount of sleep you needed? & 1 & 2 & 3 & 4 & 5 & 6 \\
\hline
\end{tabular}


Supplementary Table 2: Association between baseline sleep quality (using individual questions on the 6-item MOS sleep Scale) and odds of overall, low-grade and high-grade prostate cancer at 4-years after randomization in REDUCE.

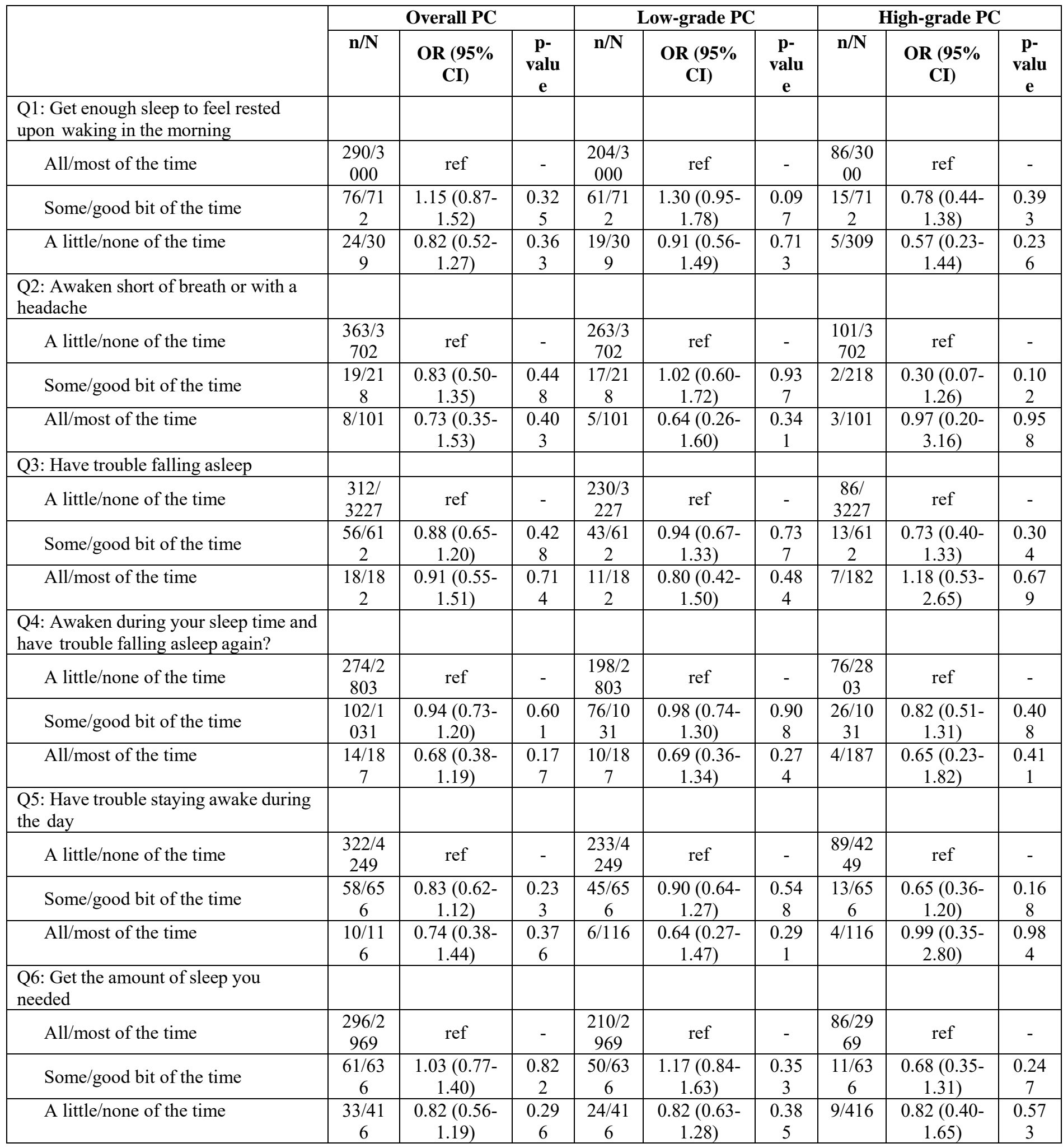


Supplemental Table 3: Association between baseline sleep score and odds of overall, low-grade and high-grade prostate cancer at 2- and 4- years after randomization stratified by IPSS score

\begin{tabular}{|c|c|c|c|c|}
\hline \multirow{2}{*}{$\begin{array}{l}\text { @ } 2 \text { years } \\
\text { Overall PC }\end{array}$} & \multicolumn{2}{|c|}{$\begin{array}{c}\text { Mild LUTS } \\
\text { (IPSS }<8, \mathrm{~N}=2,839)\end{array}$} & \multicolumn{2}{|c|}{$\begin{array}{l}\text { Moderate/Severe LUTS } \\
(\text { IPSS } \geq 8, N=2,775)\end{array}$} \\
\hline & OR $(95 \% \mathrm{CI})$ & p-value & OR $(95 \% \mathrm{CI})$ & $\mathrm{p}$-value \\
\hline \multicolumn{5}{|l|}{ Sleep score (tertiles)** } \\
\hline Low (6.0-9.0) & ref & - & ref & - \\
\hline Medium $(>6.0-12.0)$ & $1.23(0.88-1.44)$ & 0.359 & $1.00(0.75-1.34)$ & 0.976 \\
\hline $\operatorname{High}(>12.0-36.0)$ & $0.95(0.73-1.25)$ & 0.732 & $0.98(0.75-1.28)$ & 0.873 \\
\hline \multicolumn{5}{|l|}{ Low-grade PC } \\
\hline \multicolumn{5}{|l|}{ Sleep score (tertiles) } \\
\hline Low $(6.0-9.0)$ & ref & - & ref & - \\
\hline Medium $(>6.0-12.0)$ & $1.02(0.76-1.36)$ & 0.917 & $0.89(0.64-2.14)$ & 0.508 \\
\hline High $(>12.0-36.0)$ & $0.91(0.66-1.25)$ & 0.549 & $0.90(0.66-1.22)$ & 0.487 \\
\hline \multicolumn{5}{|l|}{ High-grade PC } \\
\hline \multicolumn{5}{|l|}{ Sleep score (tertiles) } \\
\hline Low $(6.0-9.0)$ & ref & - & ref & - \\
\hline Medium $(>6.0-12.0)$ & $1.39(0.92-2.09)$ & 0.115 & $1.37(0.81-2.32)$ & 0.237 \\
\hline $\operatorname{High}(>12.0-36.0)$ & $1.09(0.69-1.70)$ & 0.716 & $1.25(0.75-2.06)$ & 0.394 \\
\hline (a) 4-years & \multicolumn{2}{|c|}{$\begin{array}{c}\text { Mild LUTS } \\
(\text { IPSS }<8, \mathrm{~N}=2,054) \\
\end{array}$} & \multicolumn{2}{|c|}{$\begin{array}{c}\text { Moderate/Severe LUTS } \\
(\text { IPSS } \geq 8, N=1,967)\end{array}$} \\
\hline \multicolumn{5}{|l|}{ Overall PC } \\
\hline \multicolumn{5}{|l|}{ Sleep score (tertiles) } \\
\hline Low (6.0-9.0) & ref & - & ref & - \\
\hline Medium $(>6.0-12.0)$ & $1.23(0.87-1.73)$ & 0.236 & $0.87(0.59-1.29)$ & 0.480 \\
\hline High $(>12.0-36.0)$ & $1.05(0.72-1.53)$ & 0.803 & $0.79(0.55-1.15)$ & 0.225 \\
\hline \multicolumn{5}{|l|}{ Low-grade PC } \\
\hline \multicolumn{5}{|l|}{ Sleep score (tertiles) } \\
\hline Low (6.0-9.0) & ref & - & ref & - \\
\hline Medium $(>6.0-12.0)$ & $1.18(0.79-1.76)$ & 0.417 & $0.84(0.53-1.32)$ & 0.443 \\
\hline High $(>12.0-36.0)$ & $1.18(0.78-1.81)$ & 0.434 & $0.76(0.49-1.16)$ & 0.203 \\
\hline \multicolumn{5}{|l|}{ High-grade PC } \\
\hline \multicolumn{5}{|l|}{ Sleep score (tertiles) } \\
\hline Low $(6.0-9.0)$ & ref & - & ref & - \\
\hline Medium $(>6.0-12.0)$ & $1.39(0.76-2.52)$ & 0.287 & $0.92(0.44-1.93)$ & 0.827 \\
\hline High $(>12.0-36.0)$ & $0.75(0.35-1.58)$ & 0.442 & $0.89(0.44-1.79)$ & 0.745 \\
\hline
\end{tabular}

*Adjusted for: Age at Baseline, race, region, DRE, family history of prostate cancer, prostate volume (log transformed), PSA (log transformed), baseline BMI, coronary artery disease, diabetes, alcohol use per day, and treatment arm.

Abbreviations: $\mathrm{PC}=$ Prostate Cancer; $\mathrm{OR}=$ Odds Ratio; $\mathrm{CI}=$ Confidence Interval; LUTS=Lower Urinary Tract Symptoms; IPSS=International Prostate Symptom Score

Mild LUTS was defined as IPSS $<8$ and moderate/severe LUTS as IPSS $\geq 8$

**derived by assigning a score from 1-6 to the responses for each sleep question and summing the scores across all 6 questions. This resulted in a composite sleep score with a range of 6-36, which was subsequently categorized into tertiles. Higher scores indicate a greater severity of sleep disturbance. 
Supplemental Table 4: Association between baseline sleep score and odds of overall, low-grade and highgrade prostate cancer at 2-years after randomization in REDUCE, stratified by nocturia.

\begin{tabular}{|c|c|c|c|c|}
\hline & \multicolumn{4}{|c|}{ Nocturia } \\
\hline \multirow{2}{*}{$\begin{array}{l}\text { @ 2-years } \\
\text { Overall PC }\end{array}$} & \multicolumn{2}{|c|}{$\begin{array}{c}\text { Yes } \\
(\mathrm{N}=886)\end{array}$} & \multicolumn{2}{|c|}{$\begin{array}{c}\text { No } \\
(\mathrm{N}=4728)\end{array}$} \\
\hline & OR (95\% CI) & p-value & OR $(95 \% \mathrm{CI})$ & $\mathrm{p}$-value \\
\hline \multicolumn{5}{|l|}{ Sleep score (tertiles)** } \\
\hline Low $(6.0-9.0)$ & ref & - & ref & - \\
\hline Medium $(>6.0-12.0)$ & $1.32(0.80-2.17)$ & 0.280 & $1.02(0.83-1.24)$ & 0.875 \\
\hline High $(>12.0-36.0)$ & $0.86(0.53-1.39)$ & 0.540 & $0.99(0.81-1.21)$ & 0.933 \\
\hline \multicolumn{5}{|l|}{ Low-grade PC } \\
\hline \multicolumn{5}{|l|}{ Sleep score (tertiles) } \\
\hline Low (6.0-9.0) & ref & - & ref & - \\
\hline Medium $(>6.0-12.0)$ & $1.14(0.63-2.05)$ & 0.663 & $0.93(0.73-1.17)$ & 0.523 \\
\hline $\operatorname{High}(>12.0-36.0)$ & $0.77(0.44-1.35)$ & 0.366 & $0.95(0.75-1.20)$ & 0.662 \\
\hline \multicolumn{5}{|l|}{ High-grade PC } \\
\hline \multicolumn{5}{|l|}{ Sleep score (tertiles) } \\
\hline Low $(6.0-9.0)$ & ref & - & ref & - \\
\hline Medium $(>6.0-12.0)$ & $1.83(0.79-4.22)$ & 0.159 & $1.27(0.90-1.80)$ & 0.176 \\
\hline High $(>12.0-36.0)$ & $1.10(0.48-2.53)$ & 0.817 & $1.12(0.79-1.60)$ & 0.525 \\
\hline (@) 4 years & \multicolumn{2}{|l|}{$\begin{array}{c}\text { Yes } \\
(\mathrm{N}=617)\end{array}$} & \multicolumn{2}{|c|}{$\begin{array}{c}\text { No } \\
(\mathrm{N}=3404)\end{array}$} \\
\hline \multicolumn{5}{|l|}{ Overall PC } \\
\hline \multicolumn{5}{|l|}{ Sleep score (tertiles) } \\
\hline Low $(6.0-9.0)$ & ref & - & ref & - \\
\hline Medium $(>6.0-12.0)$ & $1.09(0.55-2.17)$ & 0.811 & $1.06(0.81-1.40)$ & 0.670 \\
\hline $\operatorname{High}(>12.0-36.0)$ & $0.85(0.45-1.62)$ & 0.631 & $0.91(0.68-1.21)$ & 0.510 \\
\hline \multicolumn{5}{|l|}{ Low-grade PC } \\
\hline \multicolumn{5}{|l|}{ Sleep score (tertiles) } \\
\hline Low $(6.0-9.0)$ & ref & - & ref & - \\
\hline Medium $(>6.0-12.0)$ & $1.23(0.52-2.91)$ & 0.623 & $1.02(0.74-1.40)$ & 0.901 \\
\hline $\operatorname{High}(>12.0-36.0)$ & $0.87(0.39-1.94)$ & 0.737 & $0.98(0.71-1.35)$ & 0.908 \\
\hline \multicolumn{5}{|l|}{ High-grade PC } \\
\hline \multicolumn{5}{|l|}{ Sleep score (tertiles) } \\
\hline Low $(6.0-9.0)$ & ref & - & ref & - \\
\hline Medium $(>6.0-12.0)$ & $0.86(0.29-2.55)$ & 0.784 & $1.20(0.72-2.01)$ & 0.480 \\
\hline $\operatorname{High}(>12.0-36.0)$ & $0.83(0.31-2.23)$ & 0.712 & $0.70(0.39-1.26)$ & 0.235 \\
\hline
\end{tabular}

*Adjusted for: Age at Baseline, race, region, DRE, family history of PC, prostate volume (log transformed), PSA (log transformed), baseline $\mathrm{BMI}, \mathrm{CAD}$, diabetes, alcohol use per day, and treatment arm.

Abbreviations: $\mathrm{PC}=$ Prostate Cancer; $\mathrm{OR}=$ Odds ratio; $\mathrm{CI}=$ Confidence interval;

Nocturia was defined as voiding 3 or more times per night

${ }^{* *}$ derived by assigning a score from 1-6 to the responses for each sleep question and summing the scores across all 6 questions. This resulted in a composite sleep score with a range of 6-36, which was subsequently categorized into tertiles. Higher scores indicate a greater severity of sleep disturbance. 
Supplemental Table 5: Association between baseline sleep problems and PC risk, Low-grade PC and High-grade PC at 2- and 4- years after randomization stratified by age category ( $>60 \mathrm{vs} . \leq 60$ years).

\begin{tabular}{|c|c|c|c|c|}
\hline \multirow{2}{*}{$\begin{array}{l}\text { @ 2years } \\
\text { Overall PC }\end{array}$} & \multicolumn{2}{|c|}{$\begin{array}{l}>60 \text { years } \\
(\mathrm{N}=3,447)\end{array}$} & \multicolumn{2}{|c|}{$\begin{array}{l}\leq 60 \text { years } \\
(\mathrm{N}=2,167)\end{array}$} \\
\hline & OR $(95 \% \mathrm{CI})$ & p-value & OR $(95 \% \mathrm{CI})$ & p-value \\
\hline \multicolumn{5}{|l|}{ Sleep scores (tertiles) } \\
\hline Low $(6.0-9.0)$ & ref & - & ref & - \\
\hline Medium $(>9.0-12.0)$ & $1.03(0.82-1.29)$ & 0.812 & $1.17(0.84-1.63)$ & 0.364 \\
\hline High $(>12.0-36.0)$ & $0.99(0.79-1.23)$ & 0.891 & $0.96(0.69-1.34)$ & 0.804 \\
\hline \multicolumn{5}{|l|}{ Low-grade PC } \\
\hline \multicolumn{5}{|l|}{ Sleep scores (tertiles) } \\
\hline Low $(6.0-9.0)$ & ref & - & ref & - \\
\hline Medium $(>9.0-12.0)$ & $0.89(0.69-1.16)$ & 0.388 & $1.14(0.77-1.69)$ & 0.500 \\
\hline High $(>12.0-36.0)$ & $0.89(0.69-1.15)$ & 0.365 & $1.03(0.70-1.51)$ & 0.891 \\
\hline \multicolumn{5}{|l|}{ High-grade PC } \\
\hline \multicolumn{5}{|l|}{ Sleep scores (tertiles) } \\
\hline Low $(6.0-9.0)$ & ref & - & ref & - \\
\hline Medium $(>9.0-12.0)$ & $1.40(0.96-2.05)$ & 0.078 & $1.23(0.68-2.22)$ & 0.500 \\
\hline High $(>12.0-36.0)$ & $1.26(0.87-1.84)$ & 0.222 & $0.78(0.41-1.45)$ & 0.427 \\
\hline @ 4 years & \multicolumn{2}{|c|}{$\begin{array}{l}>60 \text { years } \\
(\mathrm{N}=2,390)\end{array}$} & \multicolumn{2}{|c|}{$\begin{array}{l}\leq 60 \text { years } \\
(\mathrm{N}=1,631)\end{array}$} \\
\hline \multicolumn{5}{|l|}{ Overall PC } \\
\hline \multicolumn{5}{|l|}{ Sleep scores (tertiles) } \\
\hline Low $(6.0-9.0)$ & ref & - & ref & - \\
\hline Medium $(>9.0-12.0)$ & $0.97(0.71-1.34)$ & 0.851 & $1.22(0.79-1.88)$ & 0.377 \\
\hline High $(>12.0-36.0)$ & $0.99(0.72-1.35)$ & 0.940 & $0.77(0.48-1.21)$ & 0.254 \\
\hline \multicolumn{5}{|l|}{ Low-grade PC } \\
\hline \multicolumn{5}{|l|}{ Sleep scores (tertiles) } \\
\hline Low $(6.0-9.0)$ & ref & - & ref & - \\
\hline Medium $(>9.0-12.0)$ & $0.96(0.66-1.40)$ & 0.839 & $1.13(0.69-1.84)$ & 0.622 \\
\hline High $(>12.0-36.0)$ & $1.12(0.78-1.60)$ & 0.541 & $0.70(0.41-1.18)$ & 0.177 \\
\hline \multicolumn{5}{|l|}{ High-grade PC } \\
\hline \multicolumn{5}{|l|}{ Sleep scores (tertiles) } \\
\hline Low $(6.0-9.0)$ & ref & - & ref & - \\
\hline Medium $(>9.0-12.0)$ & $0.99(0.57-1.70)$ & 0.958 & $1.63(0.67-3.97)$ & 0.284 \\
\hline High $(>12.0-36.0)$ & $0.71(0.39-1.27)$ & 0.243 & $1.06(0.42-2.67)$ & 0.905 \\
\hline
\end{tabular}

*Adjusted for: Race, region, DRE, family history of PC, prostate volume (log transformed), PSA (log transformed), baseline BMI, IPSS score, CAD, diabetes, alcohol use per day, and treatment arm.

Abbreviations: $\mathrm{PC}=$ Prostate Cancer; $\mathrm{OR}=$ Odds ratio; $\mathrm{CI}=$ Confidence interval

**derived by assigning a score from 1-6 to the responses for each sleep question and summing the scores across all 6 questions. This resulted in a composite sleep score with a range of 6-36, which was subsequently categorized into tertiles. Higher scores indicate a greater severity of sleep disturbance. 
